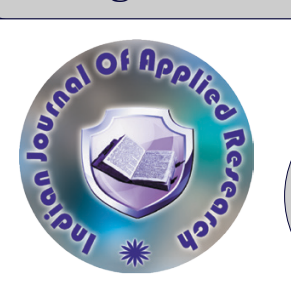

Roja Rani Ch*

Durgesh V

Venugopala Rao B Professor, Department Of Anatomy, Government Medical College, Siddipet.
Anatomy

\section{A STUDY OF THE MORPHOLOGICAL FEATURES OF THE HUMAN THORACO-ABDOMINAL DIAPHRAGM IN FOETUSES}

Associate Professor, Department Of Anatomy, NRIIMS, Visakhapatnam, Andhra

Pradesh *Corresponding Author

Professor, Department Of Anatomy, MIMS, Nellimarla, Vizianagaram.

ABSTRACT BACKGROUND: An incidence of 1 in 4000 of diaphragmatic hernias certainly warrants a thorough study especially in the light of possible noninvasive diagnostic techniques and treatment in utero. AIM: Study of the diaphragm in various gestational stages. OBJECTIVES: In-depth study of the thraco-abdominal diaphragm in fetuses was done as there is a paucity of literature. Morphometry of various aspects like attachments, foramina, blood supply and nerve supply. The major openings of the diaphragm were observed and as many structures as discernable were elucidated. The findings are compared with those of adult cadavers. METHODS: 50 Fetuses of both sexes were procured from ANITS and KGH, Visakhapatnam and 10 adult cadavers were acquired from the Department of Anatomy from NRIIMS, Visakhapatnam for the study. RESULTS: Variation of origin of inferior phrenic arteries were found. The accessory phrenic nerve was found arising from the nerve to subclavius. The eventration of the left dome of the diaphragm and oesophageal hiatus hernia with atretic lung were observed. CONCLUSION: Such a comprehensive study is of immense value for the detection of relevant hernias of the diaphragm in early intrauterine life by the clinicians and for alleviation of such disorders by surgical measures.

KEYWORDS : Congenital Diaphragmatic Hernia, Surgical Repair, Foetal Diaphragm, Morphometry, Phrenic Nerve

\section{INTRODUCTION}

Since the time of Leonardo De Vinci the diaphragm has been the subject of many investigations because of its complex development from different sources. It exhibits functional versatilities as evidenced by its smooth rhythmic respiratory movements in contrast to the spasmodic the contraction in hiccough and the more sustained arrhythmic contractions which assist defecation and parturition.

The diaphragm is the dome-shaped muscluo-aponeurotic partition between the thorax and the abdomen. It has a rounded cupola on each side below the lungs, and a depressed median portion on which the heart lies. The median portion rises to the level of the xiphisternal joint. The right cupola rises to the 5 th rib; the left cupola rises to the $5^{\text {th }}$ interspace. The shape of the diaphragm differs in adults and fetuses. The diaphragm in adults is at a higher level than in foetuses. The adult diaphragm is greater in its anteroposterior diameter, while in the case of fetuses both the Anteroposterior \& transverse diameters are approximately equal ${ }^{1}$

Several structures pierce it, passing from a region of lesser one to that of greater pressure which explains herniation through the diaphragm congenital or acquired. Most of the neonatal deaths are due to maldevelopment of the diaphragm and were mistaken for pulmonary complications. Even after Roentgen examinations were available many diaphragmatic hernias were unrecognized. The subphrenic spaces are very important after abdominal surgery like cholecystectomy, appendicitis and gastric perforation as pus can accumulate with multiple abscesses. Presuming that the anatomical arrangements were designed for a certain functional result, some inferences have been drawn regarding oesophageal hiatus, sliding hernia and reflux oesophagitis complained of during pregnancy.

\section{MATERIALS AND METHODS}

10 cadavers from NRIIMS during 2019-2020 and 50 (22 male and 28 female) foetuses received from Anil Neerukonda hospital and KGH, Visakhapatnam were chosen for the study. The fetuses were fresh specimens from labor rooms from MTP cases and were embalmed with $10 \%$ formalin and alcohol.

\section{OBSERVATION}

The diaphragm is dome-shaped, with its concave surface directed towards the abdomen. Its periphery consists of muscular fibers that are attached to the circumference of the thoracic outlet and converges into a central tendon. The muscle fibers are grouped into three parts, Sternal, Costal and Lumbar. to be inserted into the central tendon. In $5 \%$ of the cases studied, the Sternal fibers have taken origin from the xiphisternal joint, in $10 \%$ from the aponeurosis of Transverses Abdominis muscle and in rest from the xiphoid process. $10 \%$ of the fibers were partly aponeurotic, in $10 \%$ of the specimens there was a small interval in between the sternal fibers. In $10 \%$ of specimens, there was a small interval between costal and sternal fibers, through which a few lymphatic and branches from superior epigastric vessels passed. The average lengths of the Sternal fibers were 5 to $8 \mathrm{~cm}$ in adult males 4 to $7 \mathrm{Cm}$ in adult females 0.4 to 1.5 $\mathrm{cm}$ in fetuses.

Costal part arises by six fleshy slips on each side from the inner surface of the cartilage and the adjacent parts of the lower six ribs interdigitating with the transversus abdominis. It is inserted into the whole length of the central tendon. In the present study, the origin of the costal fibers extended to the ends of bony ribs in the case of the lower four ribs. The fibers consisted of fleshy digitations separated by a very narrow interval from fibers of transversus abdominis. In $70 \%$ of the specimens, musculophrenic vessels pierced the diaphragm between 8th and 9th intercostal space. The length of the fibers varied from 5 to $15 \mathrm{~cm}$ and the width from 2 to $6 \mathrm{~cm}$. in adults.

The lumbar part arises from the medial and lateral lumbo-costal arches and from the lumbar vertebrae by two pillars or crura. In the present series the lumbo-costal arches are tendinous in adults and muscular and not well-formed in fetuses. The length of the median arcuate ligament varied from 3 to $5 \mathrm{~cm}$ and that of the lateral arcuate ligament varied from 3 to $6 \mathrm{~cm}$. In the case of the foetuses, the corresponding lengths were 0.3 to 0.5 and -0.4 to $-0.6 \mathrm{~cm}$. In the present study of the two crura, right and left are arising from the upper lumbar vertebrae. The lengths of the crura in adults were 12 to $17 \mathrm{~cm}$ and in foetuses they were 2 to $6 \mathrm{~cm}$. In adult origin of crura was by separate slips uniformly while in fetuses only $48 \%$ only. The origin of the crura by a single tendon was observed $30 \%$ in fetuses. In the remaining specimens among the adults and foetuses the origin of the crura varied from a combination of different vertebrae.

The central tendons trifoliate in shape were thick in adults and were thin and small in foetuses. In foetuses $43 \%$ were thick, $40 \%$ were thin and $17 \%$ were muscular. The right and left leaves measured 12 to $25 \mathrm{~cm}$ in adults and 2 to $6 \mathrm{~cm}$ in fetuses.

The size of the inferior vena caval opening varied from 1.5 to $5 \mathrm{~cm}$ in adults and from 0.5 to $1 \mathrm{~cm}$ in fetuses. Their level in adults was at the eighth thoracic vertebra in $34 \%$, at the ninth thoracic vertebra in 64.5 $\%$ and at the tenth thoracic vertebra in $1.5 \%$. In fetuses $37 \%$ of the openings were at the level of the eighth thoracic, $63 \%$ were at the level of ninth thoracic and none at the level of the tenth thoracic vertebra. 
Fasciculi of tendinous fibers which surround the opening are absent in the cases of fetuses.

The average size of the esophageal opening varied from 1.8 to $8 \mathrm{~cm}$ in adults and $0.5 \mathrm{~cm}$ to $1 \mathrm{~cm}$ in fetuses. In adults, its level varied between the $9^{\text {th }}$ and $11^{\text {th }}$ thoracic vertebra and in fetuses at the 9 th in $5.7 \%$, at $10^{\text {th }}$ in $71.3 \%$ and at $11^{\text {th }}$ in $23 \%$ of specimens. In $5 \%$ of specimens, wide gaps were observed above and below the esophageal opening. Structures observed to pass through were, right and left vagus nerve and branches of left gastric vessels.

The size of the aortic opening varied from 1.5 to $3 \mathrm{~cm}$ in adults and from 0.5 to $1 \mathrm{~cm}$ in fetuses. The level of the aortic opening in adults was at the twelfth thoracic vertebra and in fetuses this level varied from $\mathrm{T} 11, \mathrm{~T} 12$ and $\mathrm{L} 1$ in $2.7 \%, 54.3 \%$ and $43 \%$ respectively. Cisterna chyli accompanied the abdominal aorta on its right side in $50 \%$ and the thoracic duct posteriorly in $30 \%$. It transmitted right and left lymphatic ducts in $20 \%$, the azygos vein in $20 \%$, the hemiazygos vein in $2 \%$, the greater splanchnic nerve in $3 \%$ and the lesser splanchnic nerve in 9 $\%$ (Table-I).

The greater and lesser splanchnic nerves passed through the crura in 40 $\%$ and the subcostal vessels passed behind lateral lumbo-costal arch in $80 \%$ of specimens. The sympathetic chain however passed behind the medial lumbo costal arch in all the specimens.

The blood supply is mainly from the inferior phrenic artery originating from the abdominal aorta. In the present study, inferior phrenic arteries arose from a common stem in $18 \%$ and $8 \%$ from the abdominal aorta and the celiac artery respectively and independently from $7 \%$. They are also arising from the renal artery ( $5 \%$ ) left epigastric artery $(5 \%)$ and from the suprarenal artery right and left $(6 \%)$. The musculophrenic artery supplied the diaphragm by entering through the intercostal spaces $7^{\text {th }}$ and $8^{\text {th }}$ in $40 \%, 8^{\text {th }}$ and $9^{\text {th }}$ in $20 \%$ and $9^{\text {th }}$ and $10^{\text {th }}$ in $10 \%$ of specimens. In the present study, the inferior phrenic vein drains into the inferior vena cava in $90 \%$ of specimens on the right side. The left inferior phrenic vein accompanies the left inferior phrenic artery and ends in suprarenal veins in $10 \%$ of specimens(Table-II).

In the present study no variation in the course and relations of the phrenic nerve were noticed. The left phrenic nerve was longer than the right in all the specimens. The terminal branches were three to seven in $5 \%$ of the specimens. The posterior branch was longer and divided higher up in $30 \%$ of adult specimens. The anterior and lateral branches have taken origin from a common trunk in $40 \%$ of adult specimens and $60 \%$ of foetal specimens. The accessory phrenic nerve was found arising from nerve to subclavius in $27 \%$ of the specimens (Figure-1).

Congenital defects of the diaphragm are explained on the basis of its embryology. The most common is the persistence of the pleuroperitoneal canal commonly the left one. Oesophageal hiatus is the most common type of diaphragmatic hernias, $98 \%$ of the diaphragmatic hernias occur through oesophageal hiatus(Figure-2). The anatomical arrangements at the hiatus are designed for a functional result such that deductions could be made from the study about the mechanism of the oesophageal hiatus. The strength of the hiatus depends on the muscles surrounding it. There were longitudinal bands stretching from the crura to the central tendon and oblique and crossing muscle fibers. In one foetus eventration of the left dome of the diaphragm was observed. In another case, oesophageal hiatus hernia with an atretic lung was observed(Figure-3).

\section{DISCUSSION}

Morgagni hernia, the anterior hernia is due to a defect in the sternal origin. It is extremely rare. In this, the sternal fibers originate from the xiphisternal joint. Sometimes either of the domes of the diaphragm remains thin with very few muscle fibers. Such hypoplasia leads to eventration. Origin from the sternum may be absent, but this variation was not seen in any of the specimens of the present study.

The costal origins may extend to the sixth or seventh to the fifth rib. The slip from the $12^{\text {th }}$ rib may be absent and if this be associated with an absence from the fibers from the lateral arched band, the trigonum lumbocostalis becomes an extensive gap. These variations are not seen in the present study.

In the present study, the lumbo-costal arches are tendinous in adults and muscular and not well-formed in fetuses. The standard anatomical

pattern of the right and left crura is with large right crus and small left crus. As mentioned earlier any anatomical and morphological variations bears a functional relationship, the meeting point and decussation of the muscle fibers forming the crura over the aorta and oesophagus are of significant importance. The absence of central tendon and anterior portion of the diaphragm is described by $\mathrm{O}$ Brien.

The inferior phrenic artery arising from the abdominal aorta is the main feeder artery. In the present study, they were arising from a common stem from the abdominal aorta and celiac artery. They were also arising from the renal artery, left epigastric artery and suprarenal artery which was also observed by Greig \& Gürses et al .

No variation in the course and relations of the phrenic nerve was noticed. The course and mode of division and distribution of the phrenic nerve are remarkably constant ${ }^{5}$. Though the accessory phrenic nerve was described as arising from varied sources like hypoglossal ${ }^{6}$, the spinal accessory nerve ${ }^{7}$ or with Vagus ${ }^{8}$. In the present study, the accessory phrenic nerve was arising from the nerve to subclavius. Our findings correlated with those of Rajanna.

The most frequent sites of herniation are foramen of Morgagni, Bochdalek or Pleuroperitoneal canals, the dome of the diaphragm, posterior part of the diaphragm and Oesophageal hiatus. The oesophageal hiatus is found by the overlapping of the right and left crus of the diaphragm ${ }^{10}$. However, there are many variations of how the crura come together embracing the hiatus. In the present study, oesophageal hiatus hernia with atretic lung was observed this is consistent with the findings of Collis, Listerud and Harkins who described different types of arrangement of crural overlap. The most common type is the one in which the right crus divides into 2 bundles and the left crus joins the left branch to form the left hiatal margin.

\section{SUMMARY}

The anatomy of the diaphragm has been studied with particular reference to its origin and musculature in different parts. The shape of the diaphragm was found to be different in the adults and the fetuses. The sternal fibers are aponeurotic in $10 \%$ of the specimens. Defect in these sternal fibers as described by Morgagni is of surgical importance. A defect in the costal origin in $15 \%$ of the subjects accounted for foramen of Bochdalek.

The congenital diaphragmatic hernia was demonstrated showing the stomach herniating into the left thoracic cavity leading to a collapsed lung. The study of the phrenic nerve is important in view of thoracic surgical operations and traumatic injuries of the chest and in the surgical intervention in such cases which includes repair of diaphragmatic hernias.

\section{CONCLUSION}

It may be stated that the present study provides details of the morphology of diaphragm in various gestational stages and adds to normative data to the existing literature. The importance of congenital hernias is its occurrence of one in $4000,90 \%$ presenting in the first year of life. The mortality rate is found to be $45 \%-35 \%$ and the majority is of the Bochdalek type. This is due to an improper migration of the diaphragmatic musculature. Hypoplasia of the lung has its etiological backdrop directly to Morgagni and Bochdalek's hernias. Familial occurrence and chromosomal abnormalities contribute to $2 \%$ of all congenital diaphragmatic hernias._Recent advances in imagiology especially Magnetic Resonance Imaging (MRI) in pregnant woman enables the clinicians to detect a defect in the diaphragm as early as the $10^{\text {th }}$ week of intrauterine life. This helps the correction of a potential herniation as early as the $24^{\text {th }}$ week by in utero pediatric thoracic surgery.

\section{Source of Funding: None. \\ Conflict of Interest: None.}

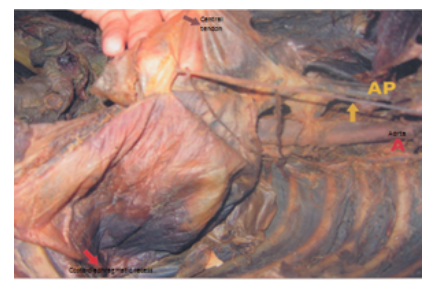

Figure-1: Accessory phrenic nerve (AP) 


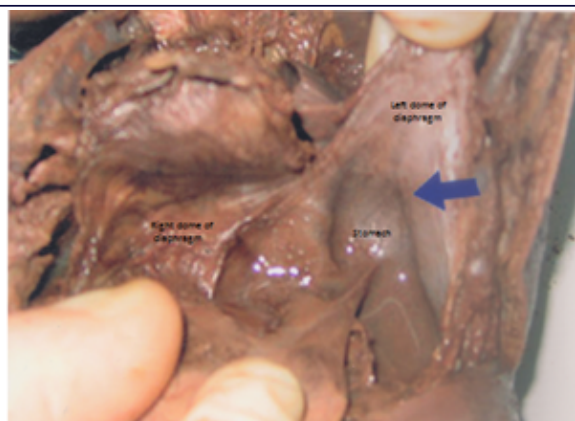

Figure-2: Oesophagial hiatus henia

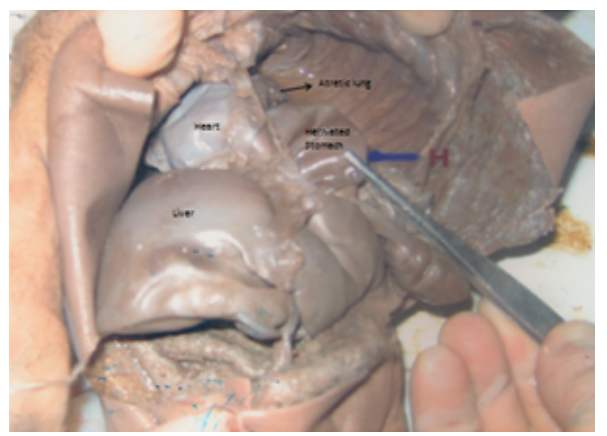

Figure-3: Congenital eventration of the left dome. Stomach has herniated into the left hemi thorax. Arrow shows $8^{\text {th }}$ intercostals space.

Table No. I. Diaphragm Size \& Levels Of Large Opening

\begin{tabular}{|c|c|c|}
\hline Description & $\begin{array}{l}\text { Adults } \\
{[10 \text { Specimens] }}\end{array}$ & $\begin{array}{l}\text { Foetuses } \\
{[50 \text { Specimens }]}\end{array}$ \\
\hline $\begin{array}{l}\text { AORTIC OPENING: } \\
\text { Size [ Diameter ] } \\
\text { 11th Thoracic Vertebra } \\
\text { 12th Thoracic Vertebra } \\
\text { 1st Lumbar Vertebra }\end{array}$ & $\begin{array}{l}1.5 \text { to } 3 \mathrm{~cm} \\
0 \% \\
40 \% \\
60 \%\end{array}$ & $\begin{array}{l}0.5 \text { to } 1.0 \mathrm{~cm} \\
2.7 \% \\
54.3 \% \\
43 \%\end{array}$ \\
\hline $\begin{array}{l}\text { INFERIOR VENA CAVAL } \\
\text { OPENING: } \\
\text { Size [ Diameter ] } \\
\text { 8th Thoracic Vertebra } \\
\text { 9th Thoracic Vertebra } \\
\text { 10th Thoracic Vertebra }\end{array}$ & $\begin{array}{l}1.5 \text { to } 3 \mathrm{~cm} \\
34 \% \\
64.5 \% \\
1.5 \% \\
\end{array}$ & $\begin{array}{l}0 \\
.5 \text { to } 1.0 \mathrm{~cm} \\
37 \% \\
63 \% \\
\mathrm{Nil} \\
\end{array}$ \\
\hline $\begin{array}{l}\text { OESOPHAGEAL } \\
\text { OPENING: } \\
\text { Size [ Diameter ] } \\
\text { 9th Thoracic Vertebra } \\
\text { 10th Thoracic Vertebra } \\
\text { 11th Thoracic Vertebra }\end{array}$ & $\begin{array}{l}1.8 \text { to } 8 \mathrm{~cm} \\
3 \% \\
81.5 \% \\
154 \% \\
\end{array}$ & $\begin{array}{l}0.5 \text { to } 1.0 \mathrm{~cm} \\
5.7 \% \\
71.3 \% \\
23 \% \\
\end{array}$ \\
\hline
\end{tabular}

Table No. II Arterial Supply Of Diaphragm: Variation Of Inferior Phrenic Artery

\begin{tabular}{|c|c|c|c|}
\hline Artery & Origin & \begin{tabular}{|l|} 
Percentage \\
Incidence \\
In 850 \\
Specimens*
\end{tabular} & \begin{tabular}{|l|} 
Percentage \\
Incidence \\
in 10 \\
specimens
\end{tabular} \\
\hline $\begin{array}{l}\text { Right Inferior Phrenic Arteries } \\
\text { Right Inferior Phrenic Arteries } \\
\text { Left Inferior Phrenic Arteries } \\
\text { Left Inferior Phrenic Arteries } \\
\text { Right \& Left by Common Stem } \\
\text { Right \& Left by Common Stem } \\
\text { Both separately from } \\
\text { Both separately from } \\
\text { Right \& Left } \\
\text { One from Coeliac \& One from } \\
\text { Aorta } \\
\text { One from Renal \& One from } \\
\text { Aorta } \\
\text { One from Aorta \& One from } \\
\text { Left gastric artery } \\
\text { One from Aorta \& One from } \\
\text { Coeliac }\end{array}$ & \begin{tabular}{|l|} 
Aorta \\
Coeliac \\
Aorta \\
Coeliac \\
Aorta \\
Coeliac \\
Coeliac \\
Aorta \\
Coeliac \& \\
Aorta
\end{tabular} & $\begin{array}{l}46.1 \\
41.1 \\
44 \\
52 \\
18.5 \\
12.2 \\
20.9 \\
12.7 \\
14.8 \\
3.8 \\
3.1 \\
3.1 \\
7.5\end{array}$ & $\begin{array}{l}40 \\
20 \\
40 \\
20 \\
10 \\
10 \\
20 \\
20 \\
40 \\
20 \\
10 \\
10 \\
20\end{array}$ \\
\hline
\end{tabular}

\section{REFERENCE}

1. Gray's Anatomy, 35th Edition, Warwick, R., and Williams, P. eds. Longman 1973

2. O'Brien, H. D.: Pericardio-peritoneal communication; description of rare type of diaphragmatic hernia, J. Anat. 74:131,1939.

3. Greig HW, Anson BJ, Coleman SS. The inferior phrenic artery: types of origin in 850 body-halves and diaphragmatic relationship. Q Bull Northwest Univ Med Sch. 1951;25:345-50. [PMC free article] [PubMed] [Google Scholar]

4. Gürses İA, Gayretli Ö, Kale A, Oztürk A, Usta A, Şahinoğlu K. Inferior Phrenic Arteries and Their Branches, Their Anatomy and Possible Clinical Importance: An Experimental Cadaver Study. Balkan Med J. 2015;32(2):189-195. doi:10.5152/balkanmedj.2015. 150052

5. Mitchell R and AS Wilson 1972: Studies on the phrenic Nerve and Diaphragmatiac plexus in Rabbits and Gerbils. Thorax, 27: No.2,195-206

6. Turner, W. (1893) A phrenic nerve receiving a root of origin from the descendens hypoglossi. J. Anat. Physiol. 27:427.

7. Felix,W.(1922).Dtsch.Z.Chir.,171,283

8. Wrisberg,H.A.(1780).DeNervisViscerumAbdominalium, Section1.Dieterich, Goettingen.

9. Rajanna MJ: Anatomical and surgical consideration of the phrenic and accessary phrenic nerves. J Int Coll Surg 1947; 10:42-52.

10. Collis JL, Kelly TD, Willey AM. Anatomy of the crura of the diaphragm and the surgery of hiatus hernia. Thorax 1954; 9:175-189.

11. Listerud MB, Harkins HN. Variations in the muscular anatomy of the esophageal hiatus: based on dissections of two hundred and four fresh cadavers. West J Surg Obstet Gynecol 1959;67:110-112; discussion 112-113.Wrisberg,H.A. (1780). DeNervis ViscerumAbdominalium,Section1.Dieterich,Goettingen. 